19. Not better; bowels have not been opened. Repeat powder until the bowels are well opened; afterwards the drops.

23. Pain across the loins; testicle still painful, and of a uniform hardness, the upper portion having become more dense. Hydriodate of potash, seven grains; fifteen drops of tincture of hyoscyamus with an ounce of water every four hours.

26. Pain much relieved in the testicle and removed from the loins. Repeat medicines.

30. Pain entirely gone; the hardened condition of the testicle remaining. Repeut medicines, and blue pill, five grains, every night.

Dec. 7. Testicle softer: quite free from pain; urethral discharge continues. Injection of sulphate of zinc, half a drachm, to a pint of water. Copaiba mixture thrice daily.

21. Quite recovered.

In putting the treatment of swelled testicle above advocated to the test, it has been found necessary to vary the treatment according to the complication; that is, to add to the sedative mixture the remedy best suited to remove the peculiar kind of infammatory action which might have been set up. Thus, in cases where that action partakes of a rheumatic character, colchicum or guaiacum, and where it is neuraloric, some form of iron, must be respectively employed.

** The above cases, as also others of the same nature which we have previously published, merely prove, in our opinion, that hyoscyamus is an useful adjunct in the treatment of gonorrhceal orchitis, not that alore it is calculated speedily and efficiently to cure the disease. Thus, in the first case, we see fifteen grains of jalap and five of calomel administered, the patient is directed to apply cold water to the testicle, and to remain on his back as much as possible. We have seen many a case of orchitis cured by less energetic means than these, without the use of sedative medicines. On the other hand it is well known that in acute local painful inflammation any form of sedative medicine is often beneficial. If hyoscyamus alone is brought forward as a remedy for gonorrhceal orchitis, it should not only be tried alone, without purgatives or local applications, but also comparatively. Slight gonorrhœal orchitis not unfrequently gets well with the mere aid of rest and a proper regimen.

\section{THE THEORY OF ATOMS.}

\section{To the Editor of THE LANCET.}

SIR,--Thanking you for your kind insertion of my observations on the theory of atoms, I beg to submit to your notice the following brief additional remarks. Let it be granted,

First. That electricity, or the electric finid, is an actual substance, and not a mere property of matter.

Secondly. That no two atoms of matter can occupy the same space at the same time.

The deduction from these postulates would be that the atoms or particles of the electric fluid could not penetrate a body between whose particles there are no space. Hence there must be space between the particles or atoms of electrical conductors. Your obedient servant,

Clifton, May, 1844.

$$
\text { W. SMrTH, Surgeon, \&c. }
$$

\section{RAILWAY TRAVELLING AND ABORTION.}

\section{To the Editor of THE LANCET.}

Sir, - Within twelve months railway communication has been introduced into this district of Scotland, a district inhabited by a robust and healthy population, notedly prolific, and among whom abortion in particular is rare. During that short period, however, three cases have occurred in my practice, each of which, in the most direct way, appeared to be the result of a short journey by railway. In England, where railway travelling is more common, and has been longer established than with us, extensive opportunities of observation on this point have been afforded; and if the circumstance alluded to, as a consequence of that mode of travelling, has been more than usually frequent, it must have been observed. It appears to me of no small importance that this point sliould be determined; and I know no better method of obtaining information on the subject than through the agency of THE LANCET. I am, Sir, yours faithfully,

Carluke, May 21, 1844 D. R. RANKin

\section{NEWS OF THE WEEK.}

St. Tromas's Hosprtal. -We have this week received the fullowing note from Dr. G. A. F. Wilks, in which Dr. $W$. , addressing the editor, says,-" In announcing the result of the election of assistant-physician at St. Thomas's Hospifal, in your Journal of the 18 th instant, you state that Drs. Benuett and Cohen were supported by the president. Permit me to correct an error in your informant, as $I$ have this day received the president's own authority for stating that he roted for inyself. In justice to my own position I have to request your insertion of the above."

"Since writing my letter of yesterday's date I have received from the president a letter, of which the following is a copy. May I request you to insert it ?

" 19, Hart-street, Bloomsbury, May 28."

“ 71, Cornhill, Mray 28

"Dear Sir,-Adverting to the article in The Lancet, which you read to me yesterday, I beg to say the editor has no authority from me to make the statement, nor, I should think, from the treasurer of the hospital, for I may say we were both ignorant how the other intended to vote. As far as I am concerned this is proved by the poll, for the result was not according to the vote I gave upon the occasion. I am, dear Sir, your's truly,

"John Pirie.

"To Dr. Wilks."

Patent Medicines.-A return to an order of the House of Commons, dated May 9, 1814, gives the following as the annual amount received in the last ten years for stamps issued for patent medicines, the sum of $301,894 l$., being, on an average, about $30,190 l$. a year. The amount was, in $1813,2061 l$. less than in 1535, the first year of the ten for which the return was made.

\section{MORTALITY TABLE.}

THE deaths in the metropolis for the week ending May 18th, 184t, are 862 (vice 812 ). The weekly arerage of the last five years is 946 , of the last five winters 1009

Diseases of the lungs ..................... 243-v. 241 Epidemic and contagious diseases............... 181-v. 171 Diseases of the nervous system .............. 164-v. 165 Dropsy, cancer, and diseases of uncertain seat .. 90-v. 71 Diseases of the stomach and other digestive organs $63-v$. 51 old age ............................. $53-v .37$ Diseases of the heart and blood vessels ........... 24-v. 35 Violence, privation, \&c. ................... 21-v, 12

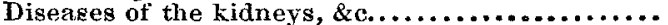
Childbirth and diseases of uterus $\ldots \ldots \ldots \ldots \ldots . . . .$. Rheumatism, diseases of the bones, \&c. ......., $6-v, 6$ Cellular diseases of the skin $\ldots \ldots \ldots \ldots \ldots \ldots \ldots \ldots . .2-v .1$

Causes not specified................................. $\frac{3}{862} \frac{2}{812}$

APOTHECARIES' HALL, LONDON.

Nayes of gentlemen who obtained certificates of qualification to practise as apothecaries on Thursday, May 23, 1844:-John Stopford Taylor, Sheffield; Charles Leeson Prince, Uckfield, Sussex Joseph Horton, Bromsgrove, Worcester; Henry Uwins; William Parkinson, Bradford, Yorkshire; Frederick Hughes Hewitt; Edmund Montomery Foster; Edwin Cullender, South Shields; William Bramwell Ferguson, Bishop Wearmouth; William Hatton, Bolton; William Rayenhill Barrington, Dublin; Thomas Wright Challinor, Liverpool.

ROYAL COLLEGE OF SURGEONS OF ENGLAND.

List of gentlemen admitted members on Friday, May 24, 1814:H. Kingsley, N. J. Dampier, T Callaway, S. J. Remnant, R. Ellis, E. S. Protheroe, R. H. Donovan, J ; M. Monllin, J. Cowburn, T. Hipwell, W. C. Byass, G F. Wills, H. Fearnside--Admitted Mon day, May $27:-J$. T. Caddy, C. J. 'Tomkins, T. Willey, W. Bourne, N. Packer, G. S. Penny, K. Tomson, S. Barnes, W. Few, C. Clarke, W. A. Biddle, C. H. Barker. 